\title{
Use of frameless intrauterine devices and systems in young nulliparous and adolescent women: results of a multicenter study
}

This article was published in the following Dove Press journal:

International Journal of Women's Health

6 August 2014

Number of times this article has been viewed

\author{
Dirk Wildemeersch' \\ Sohela Jandi² \\ Ansgar Pett ${ }^{2}$ \\ Kilian Nolte ${ }^{3}$ \\ Thomas Hasskamp ${ }^{4}$ \\ Marc Vrijens ${ }^{5}$
}

'Gynecological Outpatient Clinic and IUD Training Center, Ghent, Belgium; ${ }^{2}$ Gynecological Outpatient Clinic, Berlin, ${ }^{3}$ Gynecological Outpatient Clinic, Uetze, ${ }^{4} \mathrm{Gyn} M u ̈ n s t e r$, Münster, Germany; ${ }^{5}$ Gynecological Outpatient Clinic, Ghent, Belgium
Correspondence: Dirk Wildemeersch Gynecological Outpatient Clinic and IUD Training Center, 43-44 Franklin Rooseveltlaan, Ghent 9000 , Belgium Email d.wildemeersch@skynet.be
Background: The purpose of this study was to provide additional data on the experience with frameless copper and levonorgestrel (LNG) intrauterine devices (IUDs) in nulliparous and adolescent women.

Methods: Nulliparous and adolescent women, 25 years of age or younger, using the frameless copper IUD or the frameless LNG-releasing intrauterine system (IUS), were selected from previous studies and a current multicenter post-marketing study with the frameless copper IUD. The small copper-releasing GyneFix ${ }^{\circledR} 200$ IUD consists of four copper cylinders, each $5 \mathrm{~mm}$ long and only $2.2 \mathrm{~mm}$ wide. The frameless FibroPlant ${ }^{\mathbb{R}}$ LNG-IUS consists of a fibrous delivery system releasing the hormone levonorgestrel (LNG-IUS). The main features of these intrauterine contraceptives are that they are frameless, flexible, and anchored to the fundus of the uterus.

Results: One hundred and fifty-four nulliparous and adolescent women participated in the combined study. One pregnancy occurred with the GyneFix 200 IUD after unnoticed early expulsion of the device (cumulative pregnancy rate 1.1 at one year). Two further expulsions were reported, one with the GyneFix 200 IUD and the other with the FibroPlant LNG-IUS. The cumulative expulsion rate at one year was 1.1 with the copper IUD and 2.2 with the LNG-IUS. The total discontinuation rate at one year was low (3.3 and 4.3 with the copper IUD and LNGIUS, respectively) and resulted in a high rate of continuation of use at one year ( 96.7 with the copper IUD and 95.7 with the LNG-IUS, respectively). Continuation rates for both frameless copper IUD and frameless LNG-IUS remained high at 3 years $(>90 \%)$. There were no cases of perforations or pelvic inflammatory disease reported during or following insertion.

Conclusion: This report confirms earlier studies with frameless devices and suggests that the high user continuation rate is attributable to the optimal relationship between the IUD and the uterine cavity. IUD studies have shown that an IUD that does not fit well will often lead to side effects (ie, pain, bleeding, embedment, expulsion) and subsequent removal of the IUD. Early discontinuation is not the aim of long-acting reversible contraception.

Keywords: GyneFix ${ }^{\circledR}$, FibroPlant ${ }^{\mathbb{R}}$, frameless, intrauterine device, intrauterine system, efficacy, tolerance, continuation rate

\section{Introduction}

Intrauterine devices (IUDs) are long-acting reversible contraceptive (LARC) methods suitable for use by nulliparous and adolescent women. Sufficient evidence has shown that they do not increase the long-term risk of pelvic infection and subsequent infertility. They could be an excellent option to prevent unintended pregnancy. ${ }^{1,2}$ However, studies in the 1970s and 1980s, and also recently, based on in vivo measurements of uterine cavity length and width, concluded that uterine cavities differ substantially between women and that many uterine cavities are extremely narrow. ${ }^{3-6}$ Prior to this research, 
IUD developers did not take this important factor into account. At that time, developers may have concluded that the parous uterine cavity is capable of adaptation to a larger size IUD. However, the inventor of the plastic T-shaped IUD, Dr Howard Tatum, who designed the $\mathrm{T}$ based on anatomical studies conducted on human extirpated uteri (of parous women), came to the conclusion that IUDs, in order to be well tolerated, should cause a minimum of distortion of the endometrial cavity during the maximum degree of the contraction phase. ${ }^{7}$ Ten years later, Hasson, Kurz, and others demonstrated the great disparity between uterine cavities, particularly the transverse dimensions of the cavity, which were found to be on average only $2.5 \mathrm{~cm}$ in the fundal area in nulliparous women and only marginally wider in women who had given birth. ${ }^{3-5}$ Similar dimensions were observed by Benacerraf et al in the USA using three-dimensional sonography. ${ }^{8}$ At the time of the development of the T-shape design, IUDs were not recommended for use in nulliparous women because of fear of infection and subsequent infertility, let alone for use in adolescent women. For a long time, the TCu 380A (ParaGard ${ }^{\circledR}$; Duramed, Pomona, NY, USA) was not recommended by the US Food and Drug Administration, a decision which changed in 2005 but is still in force for the Mirena ${ }^{\circledR}$ levonorgestrel intrauterine system (LNG-IUS; Bayer, Berlin, Germany).

Oral contraceptives, the contraceptive patch, and the vaginal ring are less effective in practice than IUDs, as typical pregnancy rates, during the first year, are $9 \%$ for these three methods and high discontinuation rates are observed. ${ }^{9}$ Many IUD trials in nulliparous and adolescent women have produced discouraging results (see Discussion section). It seems that there is little hope for the IUD to solve the problems of unintended pregnancies, unless IUD technology is revisited. Therefore, the challenge for researchers remains.

The frameless GyneFix ${ }^{\circledR} 200$ IUD (Contrel Research, Ghent, Belgium) has been described previously (Figure 1). ${ }^{10}$ The FibroPlant ${ }^{\circledR}$ LNG-IUS (Contrel Research) is a multicomponent system consisting of a nonbiodegradable thread, the proximal end of which is provided with a single knot. Attached thereto is a $3.5 \mathrm{~cm}$ long and approximately $1.6 \mathrm{~mm}$ wide fibrous delivery system, releasing approximately $20 \mu \mathrm{g}$ of LNG per day. The system is effective for 5 years. The fiber is fixed to the anchoring thread by means of a stainless steel clip $1 \mathrm{~cm}$ from the upper part of the anchoring knot. The anchoring knot is implanted into the myometrium of the uterine fundus like the GyneFix 200 IUD, thus permanently securing the implant in the uterine cavity (Figure 2).

A review of clinical results with the frameless copper IUDs was reported previously. ${ }^{11}$ The current report focuses on

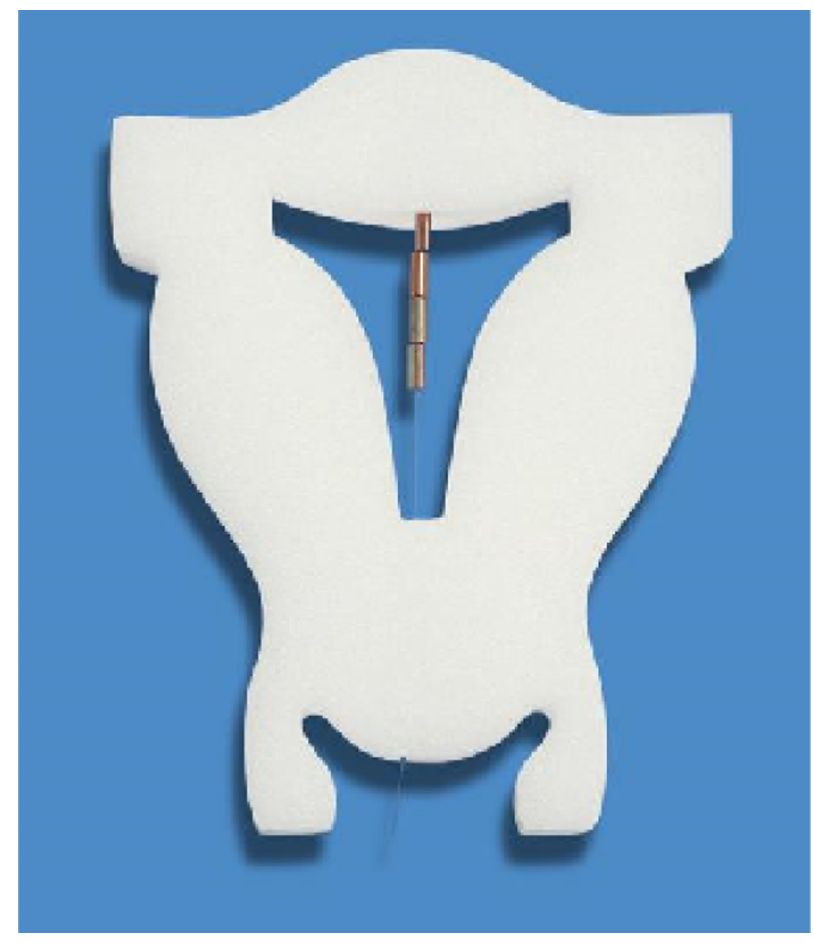

Figure I The small GyneFix ${ }^{\circledR} 200$ IUD (Contrel Research, Ghent, Belgium) is shown inserted in a foam uterus.

Notes: The GyneFix ${ }^{\circledR} 200$ IUD is only $2 \mathrm{~cm}$ long. Its small surface area is $1 / 3$ of that of the conventional T-shaped IUDs such as TCu380A (ParaGard ${ }^{\circledR}$; Duramed Pharmaceuticals Inc., Pomona, NY, USA).

Abbreviation: IUD, intrauterine device.

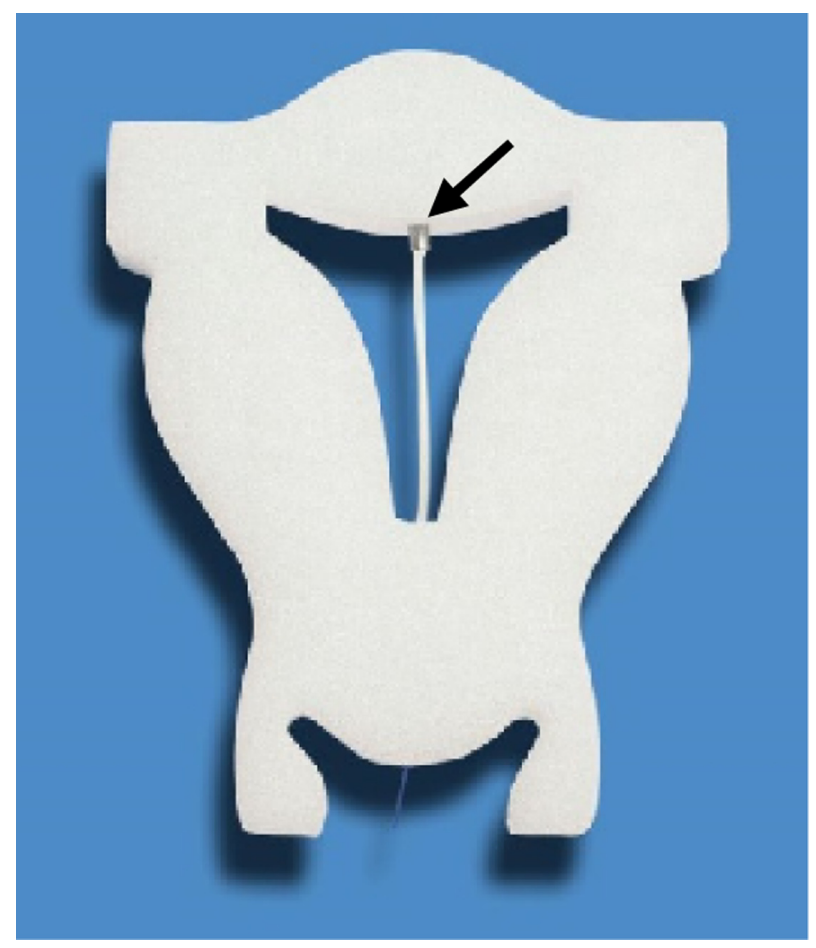

Figure 2 The FibroPlant ${ }^{\circledR}$ LNG-IUS is shown inserted in a foam uterus with stainless steel clip at the upper end (arrow).

Note: FibroPlant LNG-IUS, Contrel Research (Ghent, Belgium)

Abbreviations: IUS, LNG-releasing intrauterine system; LNG, levonorgestrel. 
the use of the small version (GyneFix 200) with an effective copper surface area of $200 \mathrm{~mm}^{2}$ and the frameless LNG-IUS in young nulliparous and adolescent women with the objective to assess their acceptability and continuation rates.

\section{Materials and methods}

The data for the current study were extracted from an earlier study $^{12}$ with the frameless copper IUD (small version) and supplemented with data recently collected from a currently ongoing post-marketing study. Data for the frameless LNGIUS in nulliparous women younger than 25 years of age and adolescent women were taken from previous contraceptive studies ${ }^{13}$ with this system.

Five centers participated. The copper IUD studies were approved by the ethics committees of the University of Ghent, Belgium, and the Tianjin Municipal Institute for Family Planning, Tianjin, People's Republic of China. Patients were also included who were participating in another study with the same copper IUD. The use of the FibroPlant LNG-IUS was approved by the ethics committee of the University of Ghent.

All participants in the study were screened as to their clinical suitability for IUD insertion and compliance with the World Health Organization eligibility criteria. ${ }^{14}$ The following were excluded: women with a history of pelvic inflammatory disease, a history of ectopic pregnancy, recent sexually transmitted disease, undiagnosed genital tract bleeding, known or suspected congenital genital tract malformation, known or suspected genital malignancy, multiple uterine fibromyomas associated with menstrual disorders, and clinical or laboratory evidence of anemia as locally defined. After gaining informed consent for participation in the study, a medical, obstetric, and gynecological history was obtained from each subject.

The subjects were requested to return for follow-up after the first menstruation and at 6 and 12 months after insertion and yearly thereafter. Women were told by the physician to return to the clinic at any time if they experienced any problems with the device and were free to return to the clinic at any time and request removal of the device.

All pertinent data at insertion and follow-up were recorded and included in an Excel (Microsoft Corporation, Redmond, WA, USA) file which was sent to the data coordinating center at the Department of Medical Informatics, University of Ghent, where they were managed according to standard procedures. The rates of discontinuation for individual reasons and groups of reasons were computed following the standard definitions used for World Health Organization contraceptive and IUD clinical trials. Life table analysis was conducted using the R statistical language environment ${ }^{15}$ (version 3.0.1), and the cumulative termination and continuation rates were computed using survival analysis methods. ${ }^{16,17}$

\section{Results}

All women were 25 years of age or younger at the time of insertion of the IUD. Insertions were done by trained providers. The age distribution of the users is shown in Table 1. One hundred and fifty-four nulliparous, including adolescent, women participated in the combined study. There were 104 GyneFix and 50 FibroPlant users. Of these women, 27 adolescents participated in the GyneFix study and 22 in the FibroPlant study, respectively. Their mean age was 20.5 \pm 3.0 (range 14-25) years. The mean duration of IUD and IUS use was $22.5 \pm 12.9$ (range 1-90) months for the GyneFix 200 IUD and $37.9 \pm 19.7$ (range 2-85) years for the LNG-IUS (Table 2).

No insertion failures occurred. The event and one-year cumulative gross rates per 100 women are presented in Table 3. One pregnancy occurred with the GyneFix 200 IUD after unnoticed early expulsion of the device (cumulative pregnancy rate 1.1 at one year). Two further expulsions were reported, one with the GyneFix 200 IUD and the other with the FibroPlant LNG-IUS. The cumulative expulsion rate at one year was 1.1 with the copper GyneFix IUD and 2.2 with the LNG-IUS. The total discontinuation rate at one year was low (3.3 and 4.3 with the copper IUD and the LNG-IUS, respectively) and resulted in a high rate of continuation of use at one year (96.7 with the copper IUD and 95.7 with the LNGIUS). Continuation rates for both the frameless copper IUD and the frameless LNG-IUS remained high at 3 years $(>90 \%)$.

Table I Age distribution of the GyneFix ${ }^{\circledR}$ and FibroPlant ${ }^{\circledR}$-LNG contraceptive users (all women $\leq 25$ years)

\begin{tabular}{lll}
\hline $\begin{array}{l}\text { Age } \\
\text { (years) }\end{array}$ & $\begin{array}{l}\text { GyneFix } \\
\mathbf{n = 1 0 4}\end{array}$ & $\begin{array}{l}\text { FibroPlant } \\
\mathbf{n = 5 0}\end{array}$ \\
\hline Mean (SD) & $20.8(2.8)$ & $19.8(3.2)$ \\
Range & $(14,25)$ & $(15,25)$ \\
\hline $\begin{array}{l}\text { Note: GyneFix, Contrel Research (Ghent, Belgium). FibroPlant, Contrel Research. } \\
\text { Abbreviation: LNG, levonorgestrel. }\end{array}$
\end{tabular}

Table 2 Distribution of the duration of usage of the GyneFix ${ }^{\circledR}$ and FibroPlant ${ }^{\circledR}$-LNG

\begin{tabular}{lll}
\hline $\begin{array}{l}\text { Duration } \\
\text { (months) }\end{array}$ & $\begin{array}{l}\text { GyneFix } \\
\mathbf{n}=104\end{array}$ & $\begin{array}{l}\text { FibroPlant } \\
\mathbf{n}=50\end{array}$ \\
\hline Mean (SD) & $22.5(12.9)$ & $37.9(19.7)$ \\
Range & $(1,90)$ & $(2,85)$ \\
\hline
\end{tabular}

Notes: Mann-Whitney U-test: $P<0.001$. GyneFix, Contrel Research (Ghent, Belgium). FibroPlant, Contrel Research.

Abbreviation: LNG, levonorgestrel. 
Table 3 Event and cumulative gross discontinuation rates per 100 women/year in 104 GyneFix ${ }^{\circledR}$ users and 50 levonorgestrel-releasing FibroPlant ${ }^{\circledR}$ contraceptive users

\begin{tabular}{|c|c|c|c|c|c|c|}
\hline & \multicolumn{3}{|c|}{ GyneFix } & \multicolumn{3}{|c|}{ FibroPlant } \\
\hline & \multirow[t]{2}{*}{$\mathbf{n}$} & \multicolumn{2}{|l|}{ Rate (SE) $95 \% \mathrm{Cl}$} & \multirow[t]{2}{*}{$\mathbf{n}$} & \multicolumn{2}{|l|}{ Rate (SE) $95 \% \mathrm{Cl}$} \\
\hline & & At one year & At 2 years & & At one year & At 2 years \\
\hline Accidental pregnancy & 1 & I.I (I.08) [0.027-6.09] & I.I (I.08) [0.027-6.09] & & - & - \\
\hline Expulsion & 2 & I.I (0.76) [0.|3-3.9I] & $2.8(1.98\}[0.34-10.24]$ & I & $2.2(2.15)[0.054-12.17]$ & $2.2(2.15)[0.054-12.17]$ \\
\hline Planned pregnancy & 1 & I.I (I.I3) [0.028-6.37] & I.I (I.I3) [0.028-6.37] & I & $2.2(2.15)[0.054-12.17]$ & $2.2(2.15)[0.054-12.17]$ \\
\hline \multirow{2}{*}{$\begin{array}{l}\text { Total use-related } \\
\text { discontinuation }\end{array}$} & 4 & $3.3(1.63)[0.89-8.44]$ & $5.1(2.47)[1.37-12.93]$ & 2 & $4.3(3.01)[0.52-15.65]$ & $4.3(3.01)$ [0.52-I5.65] \\
\hline & & & \multicolumn{3}{|c|}{ GyneFix } & FibroPlant \\
\hline \multicolumn{4}{|l|}{ Women recruited } & \multicolumn{2}{|c|}{104} & 50 \\
\hline \multicolumn{4}{|l|}{ Continuing users } & \multicolumn{2}{|c|}{97} & 47 \\
\hline \multicolumn{4}{|l|}{ Lost to follow-up } & \multicolumn{2}{|c|}{3} & I \\
\hline \multicolumn{4}{|c|}{ Woman-months of use (total period) } & \multicolumn{2}{|c|}{6,304} & 4,635 \\
\hline \multicolumn{4}{|c|}{ Cumulative continuation rate per 100 women at one year } & \multicolumn{2}{|c|}{96.7} & 95.7 \\
\hline \multicolumn{4}{|c|}{ Cumulative continuation rate per 100 women at 2 years } & \multicolumn{2}{|c|}{94.9} & 95.7 \\
\hline \multicolumn{4}{|c|}{ Cumulative continuation rate per 100 women at 3 years } & \multicolumn{2}{|c|}{94.9} & 95.7 \\
\hline
\end{tabular}

Notes: GyneFix, Contrel Research (Ghent, Belgium). FibroPlant, Contrel Research.

Abbreviations: $\mathrm{Cl}$, confidence interval; $\mathrm{SE}$, standard error.

There were neither perforations nor pelvic inflammatory disease cases reported during or following insertion.

\section{Discussion}

LARC are considered important for reducing the number of unintended pregnancies. The American College of Obstetricians and Gynecologists found that LARC methods, ie, IUDs and contraceptive implants, are safe and appropriate methods for most women and adolescents. ${ }^{18}$ Winner et al found that US women using the oral contraceptive pill, transdermal patch, or vaginal ring had a risk of contraceptive failure that was 20 times higher than the risk among those using LARC methods. ${ }^{19}$ Some reproductive health professionals have concluded that the contraceptive model should be changed by making LARC the default option, ${ }^{20}$ because improved uptake of LARC may significantly decrease the numbers of unintended pregnancies and induced abortions and generate health care cost savings by reducing contraceptive nonadherence. ${ }^{21}$ Trussell et al found that LARC methods are much more effective than short-acting reversible contraceptive methods.2. The Contraceptive CHOICE Project (CHOICE) was developed to promote the use of long-acting methods in the St. Louis region, most subjects aged 18 years and older selected intrauterine contraception $(\sim 70 \%) .{ }^{23}$ However, current IUDs have a number of drawbacks, particularly when used in young, nulliparous, and adolescent women. ${ }^{24}$

Table 4 Results with Mirena ${ }^{\circledR}$ and ParaGard ${ }^{\circledR}$ in young nulliparous and adolescent women

\begin{tabular}{|c|c|c|c|c|}
\hline $\begin{array}{l}\text { Reference } \\
\text { (study design) }\end{array}$ & IUD/IUS & Expulsion (\%) & $\begin{array}{l}\text { Removal for bleeding } \\
\text { and pain (\%) }\end{array}$ & $\begin{array}{l}\text { Continuation after } \\
6 \text { months to I year (\%) }\end{array}$ \\
\hline $\begin{array}{l}\text { Paterson et a }{ }^{25} \\
\text { Questionnaire }\end{array}$ & Mirena & 8 & ? & 85 \\
\hline $\begin{array}{l}\text { Suhonen et al }{ }^{26} \\
\text { RCT versus OC }\end{array}$ & Mirena & 1.2 & 20 & 79.8 \\
\hline $\begin{array}{l}\text { Teal et a }{ }^{27} \\
\quad \text { Retrospective }\end{array}$ & ParaGard/Mirena & $16.7 / 13.3$ & I8.2/22.7 & 55 \\
\hline $\begin{array}{l}\text { Brockmeyer et a }\left.\right|^{28} \\
\text { Prospective }\end{array}$ & ParaGard/Mirena & 7 & 17 (?) & 65 \\
\hline $\begin{array}{l}\text { Garbers et al }{ }^{29} \\
\quad \text { Retrospective ( } 6 \text { months) }\end{array}$ & ParaGard/Mirena & 4.2 & II & 74.5 (6 months) \\
\hline $\begin{array}{l}\text { Berenson et a }{ }^{30} \\
\quad \text { Large, retrospective }\end{array}$ & ParaGard/Mirena & ? & $\begin{array}{l}32.8 / 19.7(15-19 y) \\
32.0 / 21.5(20-24 y)\end{array}$ & $\begin{array}{l}79.8 / 88.2(15-19 y) \\
84.1 / 87.7(20-24 y)\end{array}$ \\
\hline $\begin{array}{l}\text { Rasheed et } \mathrm{al}^{31} \\
\quad \text { Prospective (6 months) }\end{array}$ & ParaGard & 10 & 41.7 & 58.3 (6 months) \\
\hline $\begin{array}{l}\text { Aoun et a }{ }^{32} \\
\quad \text { Retrospective }\end{array}$ & ParaGard/Mirena & 6.7 & 19.6 & 80.4 \\
\hline
\end{tabular}

Notes: ParaGard, Duramed Pharmaceuticals Inc. (Pomona, NY, US). Mirena, Bayer (Berlin, Germany).

Abbreviations: RCT, randomized controlled trial; OC, oral contraception; IUD, intrauterine device; IUS, intrauterine system; ?, unknown; y, years old. 
Table 4 provides the results of several international studies with ParaGard and Mirena in young nulliparous and adolescent women. The following comments were made by one of the authors:

Suboptimal continuation of IUDs undermines their potential to reduce unintended pregnancy. Continuation over time is the primary determinant of effectiveness for IUDs. Early discontinuation has numerous drawbacks, requiring expenditure of clinical resources and reducing the documented cost-effectiveness of the method. ${ }^{29}$

Early discontinuation also places women at risk of unintended pregnancy, as women who discontinue highly effective contraceptive methods frequently move to less effective methods. Many women who discontinue a method move to no method at all. Other authors commented that the most plausible cause of early discontinuation is disproportion between the IUD and the uterine cavity. ${ }^{30,31}$

The aim of researchers is to improve birth control methods or to find new methods that are more acceptable to women, provide a better quality of life, and are designed so that the majority of women keep using the IUD/IUS for the full approved duration of action of the device. Following a usual simple act, of insertion of the IUD/IUS, LARC have the potential to provide long-lasting protection, provided that the method is efficacious and well tolerated. Current copper IUDs have several ideal characteristics. They are highly effective, but most should be optimized to adapt to smaller uterine cavities. Shipp et al concluded that patients with embedded IUDs have a smaller fundal endometrial cavity diameter compared with those with normally placed IUDs, as documented using three-dimensional sonography of the uterus. He also suggested preprocedural three-dimensional sonography for women who are IUD candidates. ${ }^{33}$ Otero-Flores et al tested a smaller T-shaped model in Mexico and obtained good results. ${ }^{34}$ It is evident that these smaller IUDs will be better tolerated by young nulliparous women because they fit better. The study by Otero-Flores et $\mathrm{al}^{34}$ was criticized, and it was proposed to conduct a randomized comparative study between the standard TCu 380A and the smaller version to confirm that the smaller TCu 380 IUD (Duramed Pharmaceuticals Inc.) provides substantial benefits. However, one can argue about whether conducting such a study in young nulliparous and adolescent women is ethical considering the small size of the uterine cavity in the majority of these young women.

IUDs should fit like precision devices used in medicine and dentistry in general. There are many examples of designs that should fit perfectly to avoid side effects and functional problems, eg, heart valves, dental implants, and various kinds of prostheses. Vaginal rings for the management of prolapse come in several sizes, as do speculums. IUDs belong to this category of devices that need to fit well. Unfortunately, many providers still use one size for all women and insert the IUD even if the uterus is too small.

Three-dimensional sonography has shown great value in evaluating the uterine cavity, and the variation in size and shape between women has been demonstrated. Three-dimensional imaging is also valuable to determine the precise location of
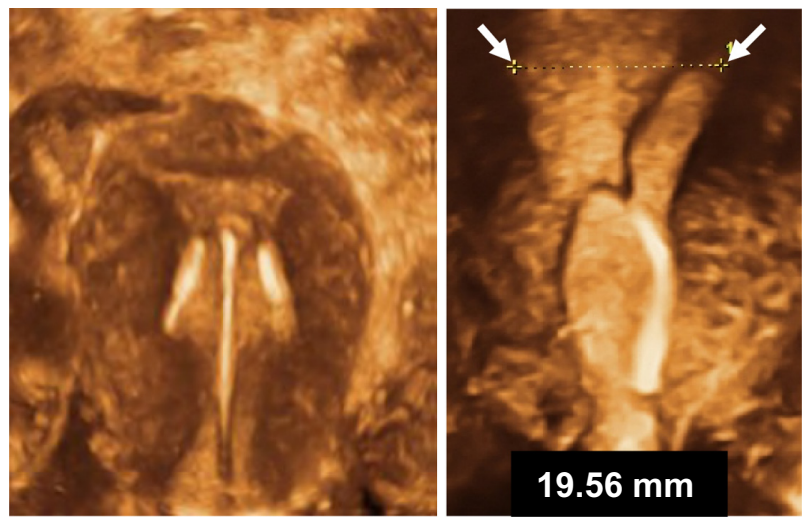

Figure 3 TCu 380A (ParaGard ${ }^{\circledR}$, Duramed Pharmaceuticals Inc., Pomona, NY, USA) intrauterine device causing bleeding and pain due to severe disproportion (left, Courtesy of Dr Shipp, Department of Obstetrics and Gynecology, Brigham and Women's Hospital, Harvard Medical School, Boston, MA, USA) and a levonorgestrelreleasing intrauterine device (Mirena ${ }^{\circledast}$ [Bayer, Berlin, Germany], right).

Notes: Both devices have a transverse arm measuring $32 \mathrm{~mm}$. The space between the arrows indicates the width of the uterine cavity.
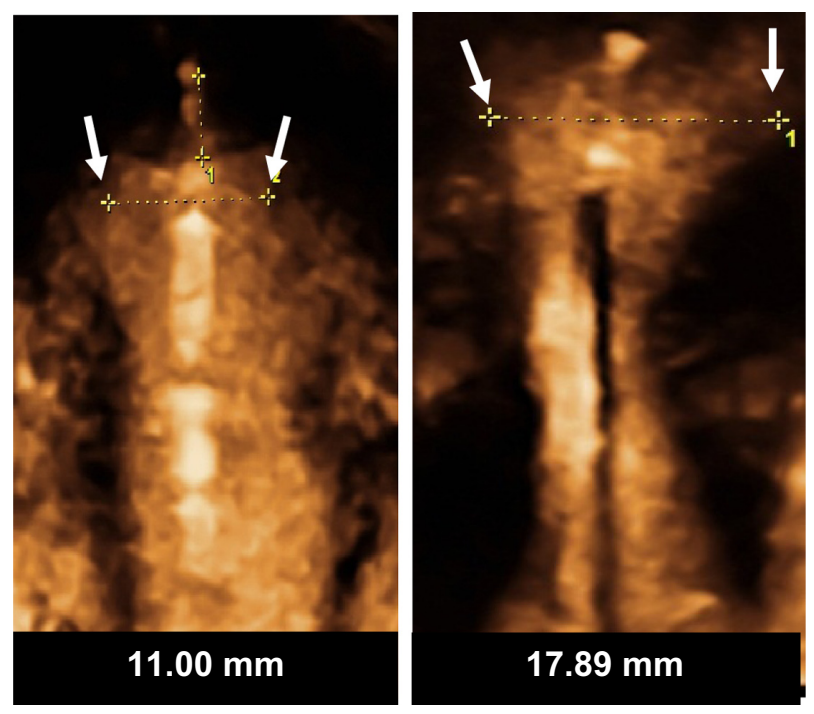

Figure 4 3-D ultrasound of GyneFix ${ }^{\circledR} 200$ IUD (Contrel Research, Ghent, Belgium) (left), illustrating the compatibility of the frameless IUD and frameless LNG-IUS (right) with very narrow uterine cavities of young adolescent and nulliparous women.

Note: The fundal width is indicated by the space between the arrows.

Abbreviations: IUD, intrauterine device; IUS, LNG-releasing intrauterine system; LNG, levonorgestrel. 
the stem and transverse arm of the IUD in the uterine cavity. Research can use this new technology to design new and improved IUDs. A new generation of IUDs could be developed which adapt to the width of the uterine cavity. Uterine cavities with a transverse diameter at the fundus of less than $20 \mathrm{~mm}$ are now seen more often (Figures 3 and 4). These small cavities are found frequently during ultrasound examination particularly in young women. On average the uterine cavity is smaller than the width of most current intrauterine contraceptives. A recent study in Finland conducted in 165 nulliparous women, fitted with a T-shaped LNG-IUS and a T-shaped copper IUD with 32 $\mathrm{mm}$ transverse arm, found a median transverse fundal diameter of the uterine cavity of $24.4 \mathrm{~mm}$. One hundred and one (62.7\%) women had a transverse diameter at the fundus of less than that. The smallest diameter was $13.8 \mathrm{~mm} .{ }^{35}$ Moreover, experience has shown that uterine cavities decrease in size as a consequence of prolonged use of the LNG-IUS. Therefore, one can question if the specialist provider should insert an IUD/IUS in a young woman without having an indication of the size of the uterine cavity. Three-dimensional imaging and hysteroscopy have shown embedded T-shaped IUDs, IUDs' retention arms that have penetrated or perforated the uterine wall, and translocation of IUDs. Figure 3 shows some examples that demonstrate the risks a woman faces when an IUD does not fit. IUDs that adapt to the volume changes of the uterine cavity and frameless IUDs could be ideal for solving incompatibility problems and the frequent side effects that lead to discontinuation.

A recent review article reports on randomized and nonrandomized studies conducted with the frameless GyneFix 200 IUD in parous and nulliparous women. ${ }^{11}$ The design of the frameless copper IUD, due to its absence of a horizontal dimension and flexibility, explains its adaptation in cavities of every size and shape. These characteristics do not allow the uterus to exert expulsive forces on the IUD, in contrast with conventional IUDs. As the smaller $200 \mathrm{~mm}^{2}$ version has efficacy similar to that of the larger $330 \mathrm{~mm}^{2}$ version, and does not significantly increase menstrual blood loss, it was thought to be more suitable for adolescent and young nulliparous women. The high effective surface area, significantly greater than that of the conventional copper IUD with its nominal surface area of $200 \mathrm{~mm}^{2}$, allows a reduction in the overall surface area of the IUD. ${ }^{36}$ The one-dimensional design of the frameless LNG-IUS explains its high acceptability and high continuation of use.

An interesting observation is that continuation rates after the first year with the frameless GyneFix 200 IUD and the frameless LNG-IUS remain high (over $90 \%$ at 5 years) due to the low rates of removal for bleeding and pain, whereas these rates reduce by up to $10 \%$ each year with conventional T-shaped IUDs. ${ }^{11}$

Figure 4 illustrates the position of the frameless IUD in the uterine cavity as well as the dimensional compatibility, even if the fundal transverse diameter is sometimes extremely small.

A drawback of this study is its relatively small patient population. A comparative study between the frameless IUD and framed IUDs would most certainly provide additional information as to the acceptability and continuation of use of these devices. Future studies should also focus on threedimensional and hysteroscopic evaluation of IUDs/IUSs, including cavity dimensions, with respect to side effects and expulsion. This study was conducted by highly experienced providers. Less experienced providers have higher insertion failure rates and should be advised to become proficient by using the uterine model (Home Uterine Trainer) provided by the manufacturer.

\section{Conclusion}

The high failure rate of short-acting contraceptive methods indicates a need to recommend LARC to young women, which once inserted can be forgotten. ${ }^{37,38}$ Many adolescent and nulliparous women prefer the IUD over non-LARC methods when they are properly informed about the advantages over short-acting methods. They are interested in safe, effective, well tolerated, and long-acting contraception. The study reported here suggests that the frameless IUD and frameless IUS, due to their optimal relationship with the uterine cavity, are well accepted, resulting in high continuation rates, which is the aim of LARC.

\section{Acknowledgment}

The authors are grateful to Professor Van Maele, Department of Medical Informatics and Statistics, University Hospital Ghent, Belgium, for statistical analysis of the data, and Dr N Goldstuck, Department of Obstetrics and Gynecology, University of Stellenbosch, Tygerberg Hospital, Western Cape, South Africa, for reviewing this paper.

\section{Disclosure}

DW has been involved in the optimization of new, innovative, drug delivery systems for use in the uterus. He is currently an advisor in devising new concepts in controlled release for contraception, gynecological treatment, and prevention of infectious diseases. The other authors report no conflicts of interest in this work. 


\section{References}

1. Farley TM, Rosenberg MJ, Rowe PJ, Chen JH, Meirik O. Intrauterine devices and pelvic inflammatory disease: an international perspective. Lancet. 1992;339:785-788.

2. Hubacher D, Lara-Ricalde R, Taylor DJ, Guerra-Infante F, GuzmanRodriguez R. Use of copper intrauterine devices and the risk of tubal infertility among nulligravid women. $N$ Engl J Med. 2001;345:561-567.

3. Hasson HM. Clinical studies of the Wing Sound II metrology device. In: Zatuchni GI, Goldsmith A, Sciarra JJ, editors. Intrauterine Contraception: Advances and Future Prospects. Philadelphia, PA, USA: Harper and Row; 1984:126-141.

4. Kurz KH. Cavimeter uterine measurements and IUD clinical correlation. In: Zatuchni GI, Goldsmith A, Sciarra JJ, editors. Intrauterine Contraception: Advances and Future Prospects. Philadelphia, PA, USA Harper and Row; 1984:142-162.

5. Kamal I, Hefnawi F, Ghonheim M, Talant M, Abdalla M. Dimensional and architectural disproportion between the intrauterine device and the uterine cavity: a cause of bleeding. Fertil Steril. 1971;22:514-521.

6. Goldstuck N. Assessment of uterine cavity size and shape: a systematic review addressing relevance to intrauterine procedures and events. Afr J Reprod Health. 2012;16:129-138.

7. Tatum HJ, Connell EB. Intrauterine devices. In: Filshie M, Guillebaud J, editors. Contraception: Science and Practice. London, UK: Butterworths; 1989.

8. Benacerraf BR, Shipp TD, Lyons JG, Bromley B. Width of the normal uterine cavity in premenopausal women and effect of parity. Obstet Gynecol. 2010;116:305-310.

9. Trussell J. Contraceptive failure in the United States. Contraception. 2011;83:397-404.

10. Wildemeersch D, Batár I, Affandi B, et al. The 'frameless' intrauterine system for long term, reversible contraception: a review of 15 years of clinical experience. J Obstet Gynaecol Res. 2003;29:160-169.

11. Wildemeersch D, Pett A, Jandi S, Hasskamp T, Rowe P, Vrijens M. Precision intrauterine contraception may significantly increase continuation of use: a review of long-term clinical experience with frameless copper-releasing intrauterine contraception devices. Int $J$ Women's Health. 2013;5:215-225.

12. Cao X, Zhang W, Zhao X, et al. Three-year efficacy and acceptability of the GyneFix 200 intrauterine device. Contraception. 2004;69:207-211. Erratum. Contraception. 2006;73:315-317.

13. Wildemeersch D, Andrade A. Review of clinical experience with the frameless LNG-IUS for contraception and treatment of heavy menstrual bleeding. Gynecol Endocrinol. 2010;26:383-389.

14. World Health Organization. Medical Eligibility Criteria for Contraceptive Use. 3rd ed. Geneva, Switzerland: World Health Organization; 2004. Available from: http://www.who.int/reproductivehealth/publications/ family_planning/9789241547710/en/. Accessed May 29, 2014.

15. R Development Core Team R. A language and environment for statistical computing. R Foundation for Statistical Computing, Vienna, Austria. 2013. Available from: http://www.R-project.org. Accessed May 29, 2014.

16. Tietze C, Lewit S. Recommended procedures for the statistical evaluation of intrauterine contraception. Stud Fam Plann. 1972;4:35-42.

17. Farley TMM. Life-table methods for contraceptive research. Stat Med. 1986;5:475-489.

18. American College of Obstetricians and Gynecologists. Committee opinion number 539: Adolescents and long-acting reversible contraception: implants and intrauterine devices. 2012. Available from: https:// www.acog.org/Resources_And_Publications/Committee_Opinions/ Committee_on_Adolescent_Health_Care/Adolescents_and_LongActing_Reversible_Contraception. Accessed May 29, 2014.

19. Winner B, Peipert JF, Zhao Q, et al. Effectiveness of long-acting reversible contraception. N Engl J Med. 2012;366:1998-2007.
20. Kaunitz A. Changing the contraceptive paradigm: making long-acting methods the default option. Medscape Today. 2012. Available from: http://www.medscape.com/viewarticle/765969. Accessed March 4, 2013.

21. Lyus R, Lohr P, Prager S. Use of Mirena ${ }^{\mathrm{TM}}$ LNG-IUS and Paragard ${ }^{\mathrm{TM}}$ CuT380A intrauterine devices for nulliparous women. Contraception. 2010;81:367-371.

22. Trussell J, Henry N, Hassan F, Prezioso A, Law A, Filonenko A. Burden of unintended pregnancy in the United States: potential savings with increased use of long-acting reversible contraception. Contraception. 2013;87:154-161.

23. Mestad R, Secura G, Allsworth JE, Madden T, Zhao Q, Peipert JF. Acceptance of long-acting reversible contraceptive methods by adolescent participants in the Contraceptive CHOICE Project. Contraception. 2011;84:493-498.

24. Hubacher D. Copper intrauterine device used by nulliparous women: review of side effects. Contraception. 2007;75:S8-S11.

25. Paterson H, Ashtin J, Harrison-Woolrych M. A nationwide cohort study of the use of the levonorgestrel intrauterine device in New Zealand adolescents. Contraception. 2009;79:433-438.

26. Suhonen S, Haukkamaa M, Jakobsson T, Rauramo I. Clinical performance of a levonorgestrel-releasing intrauterine system and oral contraceptives in young nulliparous women: a comparative study. Contraception. 2004;69:407-412.

27. Teal SB, Sheeder J. IUD use in adolescent mothers: retention, failure and reasons for discontinuation. Contraception. 2012;85:270-274.

28. Brockmeyer A, Kishen M, Webb A. Experience of IUD/IUS insertions and clinical performance in nulliparous women - a pilot study. Eur $J$ Contracept Reprod Health Care. 2008;13:248-254.

29. Garbers S, Haines-Stephan J, Lipton Y, Meserve A, Spieler L, Chiasson MA. Continuation of copper-containing intrauterine devices at 6 months. Contraception. 2013;87:101-106.

30. Berenson AB, Tan A, Hirth JM, Wilkinson GS. Complications and continuation of intrauterine device use among commercially insured teenagers. Obstet Gynecol. 2013;121:951-958.

31. Rasheed SM, Abdelmonem AM. Complications among adolescents using copper intrauterine contraceptive devices. Int J Gynaecol Obstet. 2011;115:269-272.

32. Aoun J, Dines VA, Stovall DW, Mete M, Nelson CB, Gomez-Lobo V. Effects of age, parity, and device type on complications and discontinuation of intrauterine devices. Obstet Gynecol. 2014;123: 585-592.

33. Shipp TD, Bromley B, Benacerraf BR. The width of the uterine cavity is narrower in patients with an embedded intrauterine device (IUD) compared to a normally positioned IUD. J Ultrasound Med. 2010;29:1453-1456.

34. Otero-Flores JB, Guerrero-Carreno FJ, Vazquez-Estrada LA. A comparative randomized study of three different IUDs in nulliparous Mexican women. Contraception. 2003;67:273-276.

35. Kaislasuo J, et al. presentation. In: Program of the 39th Nordic Congress of Obstetrics and Gynecology, June 10-12, 2014; Stockholm, Sweden.

36. Wildemeersch D. The effective copper surface area differs substantially between that of the frameless copper IUD and that of conventional copper IUDs: a comment. J Fam Plann Reprod Health Care. 2006;32:54.

37. Raine TR, Foster-Rosales A, Upadhyay UD, et al. One-year contraceptive continuation and pregnancy in adolescent girls and women initiating hormonal contraceptives. Obstet Gynecol. 2011;117:363-371.

38. Espey E, Ogburn T. Long-acting reversible contraceptives: intrauterine devices and the contraceptive implant. Obstet Gynecol. 2011;117: $705-719$. 
International Journal of Women's Health

\section{Dovepress}

\section{Publish your work in this journal}

The International Journal of Women's Health is an international, peerreviewed open-access journal publishing original research, reports, editorials, reviews and commentaries on all aspects of women's healthcare including gynecology, obstetrics, and breast cancer. The manuscript management system is completely online and includes

a very quick and fair peer-review system, which is all easy to use. Visit http://www.dovepress.com/testimonials.php to read real quotes from published authors.

Submit your manuscript here: http://www.dovepress.com/international-journal-of-womens-health-journal 